\title{
Sea duck predation in mussel farms: the best nets for excluding common eiders safely and efficiently
}

\author{
Élisabeth Varennes ${ }^{1, *}$, Sveinn Are Hanssen ${ }^{2}$, John Bonardelli ${ }^{3}$, Magella Guillemette ${ }^{1}$ \\ ${ }^{1}$ Département de Biologie, Chimie et Géographie, Université du Québec à Rimouski, 300, allée des Ursulines, Rimouski, \\ Quebec G5L 3A1, Canada \\ ${ }^{2}$ Norwegian Institute for Nature Research, Fram Centre, 9296 Tromsø, Norway \\ ${ }^{3}$ Shellfish Solutions AS, Trondheim 7020, Norway
}

\begin{abstract}
Shellfish aquaculture is a growing food-producing sector. The blue mussel Mytilus edulis is the primary farmed shellfish and is also a main prey for various species of sea ducks. With their large density of high-quality mussels, mussel farms attract these predators, and consequent depredation by ducks represents a substantial economic loss among mussel growers worldwide. Total exclusion with nets seems to be the only method that provides complete and long-term control of bird predation. The best nets for duck exclusion must be cost effective, efficient, easy to handle, and safe for bird populations. In order to identify the best net type, we tested 8 different nets under controlled conditions using captive common eiders Somateria mollissima, the largest sea duck species in the Northern Hemisphere. We identified a net with a maximum mesh size of 6 inches $(\sim 15 \mathrm{~cm})$ and large twine size to be best in excluding common eiders considering the above-mentioned criteria. Nets with thin twine and large mesh size were more likely to cause bird entanglement. In addition to using the best nets for sea duck exclusion, it is necessary to identify a target zone where such nets are the most effective. Good knowledge of the predation problem as well as collaboration among mussel growers, bird specialists, and government authorities are essential to reduce the costs and effort of installing and maintaining exclusion nets.
\end{abstract}

KEY WORDS: Aquaculture $\cdot$ Behavior $\cdot$ Diving $\cdot$ Netting $\cdot$ Somateria mollissima $\cdot$ Mytilus edulis

\section{INTRODUCTION}

Aquaculture is a growing food-producing sector, with an average annual growth rate of $8.3 \%$ from 1970 to 2008 (FAO 2010), and a total production of 63.6 million $\mathrm{t}$ in 2011 (FAO 2012). The shellfish aquaculture industry, which represents approximately $14 \%$ of total aquaculture production (FAO 2012), has an important economic impact throughout the world. Mussels are among the most produced marine shellfish, with a worldwide production of 1.8 million $\mathrm{t}$ in 2010 (FAO 2012). Blue mussels Mytilus edulis are produced in mussel farms either from bottom culture or in suspended culture in most coastal countries of the Northern Hemisphere, both in Europe and North

*Email: varenneselisabeth@yahoo.fr
America (FAO 2003). Different mussel culture techniques exist, but the most common method is the suspended culture, either with rafts (see Fig.4 in Rueggeberg \& Booth 1989) or long lines (see Fig. 7 in Mallet \& Myrand 1995) (Spencer 2002). The continual immersion of cultivated mussels allows a high growth rate and high ratio of flesh to shell content at commercial size (40 to $75 \mathrm{~mm}$ length; Lutz 1980, Kirk et al. 2007). Establishment depth of ropes varies according to the farm location. Generally, productivity is better at shallow depths (0 to $3 \mathrm{~m}_{i}$ Spencer 2002), but in areas subject to ice, ropes and lines may be sunk to greater depths (up to $10 \mathrm{~m}$; Mallet \& Myrand 1995).

Bivalves, and particularly mussels, are principal prey items for different sea duck species including eiders

(C) The authors 2013. Open Access under Creative Commons by Attribution Licence. Use, distribution and reproduction are unrestricted. Authors and original publication must be credited. 
(Somateria spp.), scoters (Melanitta spp.), and longtailed ducks Clangula hyemalis (Cottam 1939, Nilsson 1972, Cantin et al. 1974, Vermeer \& Bourne 1984, Guillemette et al. 1996, Leopold et al. 2001). Sea ducks feed on benthic organisms by diving at depths down to $50 \mathrm{~m}$, but generally prefer shallower waters (0 to $10 \mathrm{~m}$ ) where benthic prey are most abundant (Guillemette et al. 1993). Mussels with thinner shells and higher flesh content are generally preferred by ducks (Guillemette et al. 1996, Bustnes 1998, Hamilton et al. 1999).

Mussel farms very often contain very high densities of the preferred mussels and may thus become foraging hot spots for sea ducks (Kirk et al. 2007). This may lead to severe problems for mussel farm owners, particularly during spring and autumn, when birds have to build up their body reserves (i.e. hyperphagia, Guillemette 2001) before reproduction, migration, or wintering (Ross \& Furness 2000). Northern countries are affected to various degrees by different sea duck species (e.g. common eiders in Norway and Scotland; scoters and long-tailed ducks in Atlantic Canada; Rueggeberg \& Booth 1989, Price \& Nickum 1995, Ross \& Furness 2000, Dionne 2004).

Small mussels (average length $20 \mathrm{~mm}$ ), which are harvested on collectors, are generally the most affected by predation because of the selective behavior of sea ducks. However, ducks are able to forage on larger mussels when smaller ones are no longer available, and can cause damage to collectors as well as commercial mussel ropes. Moreover, when sea ducks forage on mussels, especially in spring and autumn, they form large flocks (hundreds to thousands of birds) that may greatly increase their impact on mussel production, causing substantial losses that often result in bankruptcy for producers if the problem is not addressed in time. The recent increase in closures spreading from Scandinavia to eastern Canada is testament to the impact of diving ducks on mussel growers (J. Bonardelli pers. obs.). For example, stock losses due to eider predation in Scotland from 1992 to 1996 varied between 10 and $30 \%$ of the total stock (Ross \& Furness 2000). In spring 2011, all mussel growers in Chaleur Bay, Québec, Canada, were severely hit by scoter (Melanitta spp.) predation, losing almost all of their collectors and one-third of their 1 to 2 yr old mussel ropes (E. Varennes pers. obs.).

Several methods have been developed to limit bird predation in aquaculture and reduce economic losses. Deterrent methods are of 2 types: (1) frightening methods (e.g. gas cannons, effigies, boat chasing, underwater acoustics) and (2) physical exclusion (e.g. underwater nets, surface wires or nets) (Draulans
1987, Galbraith 1992, Gorenzel et al. 1994, Curtis et al. 1996, Littauer et al. 1997, Falker \& Brittingham 1998). As scaring methods are subject to bird habituation and thus their efficiency decreases over time, total exclusion seems to be the only method that provides a complete and long-term control of bird predation in aquaculture facilities. Exclusion nets in mussel farming are used in some countries, including Scotland, Sweden, the USA, and Canada, where they are deployed around long-line installations or rafts with suspended mussel ropes, and apparently are effective in reducing bird predation (Rueggeberg \& Booth 1989, Ross \& Furness 2000). Nets are generally installed up to $1 \mathrm{~m}$ above the surface (see example in Rueggeberg \& Booth 1989), which seems to effectively prevent common eiders from flying above the exclusion nets and landing within the mussel farm, as long as the lines are not too far apart to allow for safe take-off and landing (less than 20 to $30 \mathrm{~m}$ apart) (J. Bonardelli pers. obs.).

The use of exclusion nets in mussel farms represents a non-negligible addition of work and cost for growers. Thus the best exclusion nets must be cost effective and easy to handle, install, clean, and remove once the birds have departed from the area. Concerning the cost, nets are generally sold by weight, such that the heaviest nets are usually more expensive and therefore less preferred by growers (Rueggeberg \& Booth 1989). Regarding handling and maintenance, nets in oceanic waters are often associated with rapid fouling, which may decrease the flow of water to the mussel site and decrease nutriment circulation within the site, thereby affecting mussel growth. Growers need to be able to easily remove and replace exclusion nets, according to weather conditions, seasons, and presence of birds.

Nets should also be safe for wild birds. Indeed, nets in open waters can represent an entanglement risk for animal populations, and this risk should be considered when installing a net in a marine system (Hall 1996, Dagys \& Žydelis 2002, Merkel 2004, Davies et al. 2009, Žydelis et al. 2009). Different factors influence entanglement risk, but one of the most important factors is the type of net used (Rueggeberg \& Booth 1989, Nemtzov \& Olsvig-Whittaker 2003).

Although exclusion nets are already being used in different countries, very few scientific studies have been done to test which types of nets are the most suitable for excluding diving ducks from mussel farms. Rueggeberg \& Booth (1989) tested different types of underwater nets in a mussel farm with scoter predation problems and quantified the presence of birds, their entries and activities into pens, and the num- 
ber of entanglements. Similarly, Nemtzov \& OlsvigWhittaker (2003) tested different types of nets to safely exclude sea birds from freshwater fishponds in Israel. However, neither of these studies had the possibility to observe detailed behavioral reactions of birds, in order to identify a net type that efficiently and safely excludes bird predators.

The common eider Somateria mollissima is the largest sea duck species, with a body mass between 1500 and $2300 \mathrm{~g}$ (Guillemette 1994, Guillemette \& Ouellet 2005, Jamieson et al. 2006) and a length between 50 and $70 \mathrm{~cm}$. Common eiders are major consumers of mussels, and large flocks of eiders foraging on mussels may lead to important prey depletion in natural mussel beds (Guillemette et al. 1996, Larsen \& Guillemette 2000) or in mussel farms (Dunthorn 1971, Galbraith 1992, Ross \& Furness 2000).

The aim of this study was to test a large selection of nets varying in mesh size, twine diameter, and material composition, under controlled conditions with captive common eiders. The objectives of this study were: (1) to determine the mesh size limit for an effective exclusion of eiders; and (2) to discuss bird interactions with nets, entanglement potential, and manageability of the experimental nets according to their characteristics (mesh size, twine diameter, and material).

\section{MATERIALS AND METHODS}

We used 7 hand-raised captive common eiders kept at the Maurice Lamontagne Institute, Fisheries and Oceans Canada. Captive birds were kept in an isolated and adapted room with 2 fiberglass tanks supplied with filtered sea water pumped in from the St. Lawrence Estuary. Water temperature and salinity in tanks followed the natural variation of the estuary (approximate temperature range: -1.3 to $11.9^{\circ} \mathrm{C}$; approximate salinity range: 23.8 to $29.9 \%$ ). Full-spectrum artificial light followed the natural photoperiod, and room temperature was maintained between 15 and $19^{\circ} \mathrm{C}$. Each tank comprised 2 sections: a pool ( $4 \mathrm{~m}$ wide $\times 6 \mathrm{~m}$ long $\times 1.5 \mathrm{~m}$ deep) and a loafing platform $(1 \times 4 \mathrm{~m})$. One tank was a holding tank where birds were kept when they were not involved in an experiment. The animals had ad libitum access to food (Mazuri ${ }^{\circledR}$ Sea Duck Diet pellets) and fresh water, as well as some live mus- sels placed at the bottom of the tank to stimulate their diving behavior. The experimental tank was equipped with 2 surface video cameras and 1 underwater video camera in order to record bird interactions with nets and their diving behavior. Experimental exclusion nets were furnished by Morenot (Norway) and distributed by Campbell River Netloft (British Columbia, Canada). We tested a large selection of nets $(n=8)$, varying principally in mesh size (3 to 12.5 inches [ca. 7.6 to $31.8 \mathrm{~cm}$ ] stretched dimensions, i.e. measure from end-to-end when mesh is pulled flat), twine diameter ('thickness'), and material composition (polypropylene or nylon) (Table 1).

Birds were tested individually in the experimental tank, with each net presented in a random order. Bird order was also determined randomly. The day before the experiment, the holding tank was emptied to catch the tested bird. The bird was then weighed and placed in the experimental tank with a duck decoy to reduce its stress due to isolation. It also had access to a mussel rope (average mussel length: $20 \mathrm{~mm}$ ) for approximately $4 \mathrm{~h}$ to encourage it to forage on rope (Fig. 1). The tested bird was then fasted until the experiment began on the following morning. On the morning of the experimental day, the mussel rope was placed back in the experimental tank, and the bird was able to pick up some mussels before the start of the experiment. To install the net, the bird was gently brought onto the platform with a pole and kept there while the experimenter installed the net along the tank width, slightly beyond the middle of the tank. The bottom of the net was weighted with a lead line in order to keep it close to the bottom of the tank, but it was not attached to the floor. The decoy and the rope were then placed on the other side of the net (Fig. 1). The bird was allowed a few minutes to calm down after net installation. The platform door was then opened and the recording sequence was

Table 1. Tested nets and their characteristics. Mesh size is given as stretched dimension, i.e. from end to end of a mesh when pulled flat

\begin{tabular}{|lccccc|}
\hline $\begin{array}{l}\text { Net } \\
\text { no. }\end{array}$ & $\begin{array}{c}\text { Mesh size in } \\
\text { inches }(\mathrm{cm})\end{array}$ & $\begin{array}{c}\text { Thickness } \\
(\mathrm{mm})\end{array}$ & Netting material & Color & $\begin{array}{c}\text { Weight } \\
\left(\mathrm{kg} \mathrm{m}^{-2}\right)\end{array}$ \\
\hline 1 & $3(7.6)$ & Thin (1.5) & Polypropylene & Black & 0.091 \\
2 & $4(10.1)$ & Thin (2) & $\begin{array}{c}\text { Nylon } \\
\text { Black }\end{array}$ & 0.073 \\
3 & $4(10.1)$ & Medium (3) & Polypropylene & Orange & 0.216 \\
4 & $5(12.7)$ & Thick (4.5) & Nylon & White & 0.406 \\
5 & $6(15.2)$ & Thin (1.5) & Nylon & Black & 0.037 \\
6 & $6(15.2)$ & Thick (3.5) & Nylon & White & 0.190 \\
7 & $8(20.3)$ & Thin (2) & Polypropylene & Black & 0.044 \\
8 & $12.5(31.8)$ & Thick (4.5) & Nylon & White & 0.158 \\
\hline
\end{tabular}



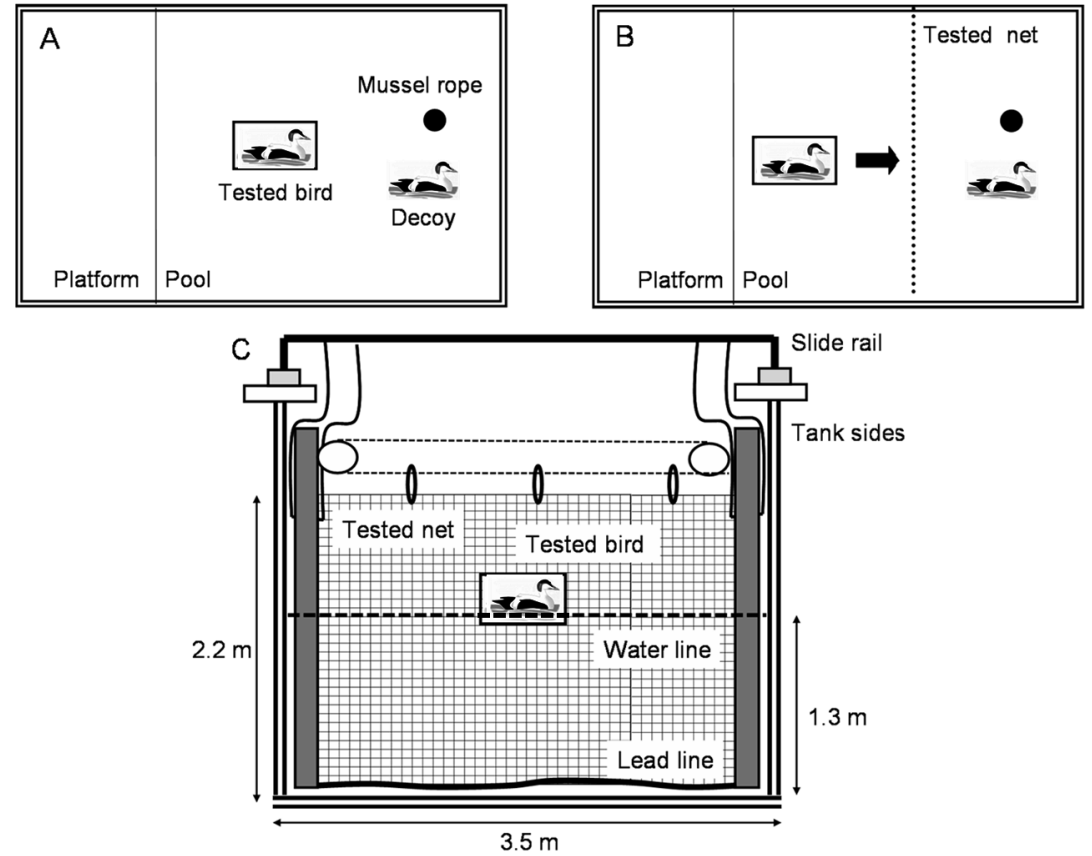

Fig 1. Experimental set-up. (A) Top view of the experimental tank during habituation. (B) Top view of the experimental tank during an experimental session. (C) Cross-sectional view with dimensions of the experimental tank during an experimental session

started. This experimental session set-up worked well for all experimental birds except one, which did not go to the platform for the net installation. We therefore modified the net installation procedure somewhat without this changing the behavior of the bird interacting with nets. The experimental session lasted $1 \mathrm{~h}$ unless the experimental bird went to the other side of the net by going through or under the net, or if it got caught in the net and the experimenter had to intervene to disentangle the individual ('complete entanglement'). At the end of the $1 \mathrm{~h}$ sequence, the bird was taken to the platform, and the tested net was removed. If the bird was already on the other side of the net, the same process was repeated but with the bird in the water instead of on the platform. The bird was then released in the tank with the decoy and the rope for several minutes to increase its motivation, and the procedure was repeated with the next experimental net. Generally, it was possible to do all nets in $2 \mathrm{~d}$. At the end of the second day, the experimental bird was caught on the platform, weighed, and put back in the holding tank. The following day, the same process was repeated with a new individual.

The mussel rope and decoy placed on the other side of the experimental net were used respectively as 'food and social motivation factors' to encourage test birds to interact with the net and to attempt to go through the nets. Moreover, the experimental birds usually preferred to stay as far away as possible from the platform (where the experimenter provided food daily), so a 'security motivation factor' was added by the disposition of the tested net. During the experiment, birds were generally motivated to interact with the net, but some individuals showed a decrease in their motivation to interact with nets after several hours spent in front of nets. To avoid this problem, only 4 nets were tested per day with periods without nets between each experimental session. During these periods, birds were able to swim in the entire tank, and were in contact with the rope and the decoy. Generally, those periods were enough to motivate the tested bird for the next net. The video sequences were analyzed by the same observer (É. Varennes) with the behavioral recording software JWatcher V1.0. Behaviors were considered events and were analyzed as the number of occurrences per experimental session (Table 2).

All statistical analyses were performed with $\mathrm{R}$ (v.2.15.2; R Development Core Team 2009). Data were analyzed with linear mixed-effect models fit with maximum likelihood (R package nlme), with nets or mesh sizes as fixed effects and bird identity as a random effect. Mesh size was used instead of nets as the fixed effect for the analysis of bird interactions with nets ('total' interactions, 'head-through' interactions, and 'other' interactions; Table 2) because we wanted to know whether the type of interaction changed according to net mesh size.

To obtain normality (tested by a Shapiro-Wilk normality test) and homogeneity of variances (tested by a Bartlett test of homogeneity of variances), some data were transformed. Approach time in seconds, for all nets and for all birds (except the one with the modified net installation procedure) were log transformed; duration in seconds spent before birds got through nets for Net 7 and Net 8 were log transformed; numbers of total interactions during a $1 \mathrm{~h}$ session for Nets 1 to 6 were square root transformed; numbers of 'head-through' interactions and numbers of 'other' interactions during a $1 \mathrm{~h}$ session for Nets 1 to 6 were $(\log +1)$ transformed. Differences, when applicable, were tested with a multiple comparison of means by Tukey contrasts (R package multcomp).

When normality and homogeneity were not verified even after transformations, data were analyzed 
Table 2. Somateria mollissima. Recorded behaviors during video analysis. Trials lasted $1 \mathrm{~h}$ unless stopped earlier (indicated with an X)

\begin{tabular}{|c|c|c|}
\hline Behavior & Trial stopped & Description \\
\hline Going through the net & $\mathrm{X}$ & $\begin{array}{l}\text { The bird goes to the other side of the net by passing through it. Duration in } \\
\text { seconds before birds went through was also recorded. }\end{array}$ \\
\hline Going under the net & $\mathrm{X}$ & The bird goes to the other side of the net by diving under it. \\
\hline Complete entanglement & $\mathrm{X}$ & $\begin{array}{l}\text { The bird becomes entangled in the net, and intervention by the experimenter is } \\
\text { needed to disentangle it. The session is stopped when the experimenter starts to } \\
\text { move the net. }\end{array}$ \\
\hline Partial entanglement & & $\begin{array}{l}\text { The bird becomes entangled in the net but is able to disentangle itself within } \\
\text { several seconds. }\end{array}$ \\
\hline Head-through interaction & & The bird gets its head through the mesh of the net. \\
\hline Diving without interaction & & Diving without any interaction with the net, usually not close to it. \\
\hline Diving with interaction & & Diving with at least 1 interaction with the net underwater. \\
\hline Other interactions & & All other interactions with the net (e.g. biting or pushing the net). \\
\hline
\end{tabular}

with Kruskal-Wallis tests and differences were tested with Mann-Whitney $U$-tests. This was the case for the duration in minutes spent swimming along the net for Nets 1 to 6 ; number of partial entanglements during a $1 \mathrm{~h}$ session for all nets except Net 8; and number of dives (total dives, dives with interactions, and dives without interactions) during a $1 \mathrm{~h}$ session for Nets 1 to 6 . All p-values were considered significant at the $\alpha=0.05$ level.

\section{RESULTS}

All birds approached nets relatively quickly (mean $\pm \mathrm{SD}$ approach time for all nets $=16 \pm 9 \mathrm{~s}$ ), with no significant differences between experimental nets $\left(F_{7,35}=0.758, \mathrm{p}=0.626\right)$. Moreover, the ducks generally spent most of the session swimming along the net (mean \pm SD duration of swimming along the tested net $=41.7 \pm 19.4 \mathrm{~min}$ in a $1 \mathrm{~h}$ session), with no significant differences between experimental nets (analysis without Nets 7 and $\left.8 ; \chi^{2}=4.630, \mathrm{df}=5, \mathrm{p}=0.463\right)$.

\section{Mesh size (3" to 12.5") and exclusion potential}

Eiders were able to go through only 2 nets, Net 7 $\left(8^{\prime \prime}\right)$ and Net $8\left(12.5^{\prime \prime}\right)$. All birds $(\mathrm{n}=7)$ went through Net 8 (mean \pm SD duration before passing through $=$ $1.3 \pm 0.7 \mathrm{~min})$, and 5 of 7 birds went through Net 7 (mean $\pm \mathrm{SD}=6.2 \pm 5.0 \mathrm{~min}$ ). Birds took significantly more time to go through Net 7 than through Net 8 $\left(F_{1,4}=23.768, \mathrm{p}=0.008\right)$. The other mesh sizes $\left(3^{\prime \prime}\right.$ to $6 "$ ) efficiently excluded birds.

Only 1 bird went under the experimental net. This was Net 3, which was the first net tested with this bird. The bird went under after 40.0 min from the start of the experimental trial and a total of 508 interactions with the net at the surface and 18 dives with underwater interactions.

\section{Mesh size (3" to 6") and number of interactions}

Birds interacted with the net principally from the surface. One of the most important interactions was when birds tried to get their head through the net ('head-through' interactions), trying several times during an experimental trial. Depending on the mesh size, this interaction was more or less possible and occurred at different intensities (the whole head and neck or only the head and the top of the neck). When birds were not able to get their head through (mesh size 3" and probably lower), they generally tried to push the net with their head, get their bill through, or bit and pulled it ('other' interactions). When we considered the sum of all interactions ('head-through' interactions plus 'other' interactions), there was no significant effect of mesh size on the number of total interactions per session $\left(F_{3,32}=2.043, \mathrm{p}=0.128 ;\right.$ Fig. 2$)$. However, there were significant differences between mesh sizes in the number of 'head-through' interactions per session $\left(F_{3,32}=7.070, \mathrm{p}<0.001\right)$, with 3 " nets significantly different from 6 " nets $(\mathrm{p}<$ 0.001), 5" nets $(\mathrm{p}<0.001)$, and 4 " nets $(\mathrm{p}=0.005$; Fig. 2). The number of other types of interactions per session was also different for the different mesh sizes $\left(F_{3,32}=5.253, \mathrm{p}=0.005\right)$, with $3 "$ nets significantly different from 6 " nets $(p=0.003)$ and $5 "$ nets $(p=0.010)$; and with $4 "$ nets significantly different from 6" nets ( $p=0.036$; Fig. 2). 


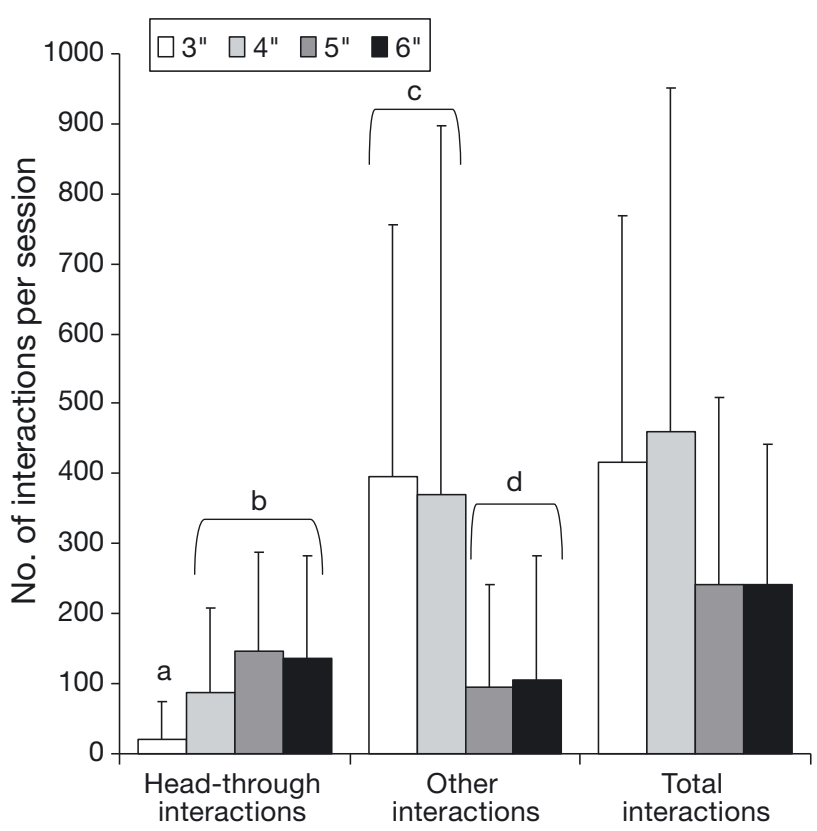

Fig. 2. Somateria mollissima. Mean \pm SD number of the 2 types of interactions ('head-through' and 'other') and the total interactions (sum of the 2 types) per $1 \mathrm{~h}$ session, according to mesh size. Values with different letters are significantly different at $\mathrm{p}<0.05$

\section{Net type effect on number of entanglements and dives}

No complete entanglement occurred with any of the nets. However, there were some partial entanglements, where the bird got caught in the net (often by its head) but succeeded in disentangling itself. Partial entanglements happened at different intensities (i.e. birds were more or less trapped in the net), but never to the point where the bird was injured or in danger. Moreover, partial entanglements always occurred at the water surface, never below the surface. The frequency of partial entanglements was also different between nets $\left(\chi^{2}=14.100\right.$, df $=6, \mathrm{p}=$ $0.030)$; however, no significant differences appeared when nets were compared 2 by 2 with MannWhitney $U$-tests. The number of entanglements was so low that it was difficult to highlight statistical differences. Nevertheless, there was a strong tendency in the mean number of partial entanglements per session, with higher numbers of partial entanglements for Net 7 and Net 5 (Table 3).

There were very few dives without interactions with the net (mean \pm SD number of dives without interactions per session for all nets except Nets 7 and $8=$ $1.38 \pm 2.81$ ), and fewer dives with interactions with the net (mean \pm SD number of dives with interactions per session for all nets except Nets 7 and $8=0.83 \pm 4.28$ ).
Table 3. Somateria mollissima. Mean \pm SD number of total dives and partial entanglements per experimental session for experimental nets. No. of dives per $1 \mathrm{~h}$ session was not calculated for Net 7 because trials ended before $1 \mathrm{~h}$ and generally with no dives

\begin{tabular}{|ccc|}
\hline Net number & No. of dives & $\begin{array}{c}\text { No. of partial } \\
\text { entanglements }\end{array}$ \\
\hline 1 & $0.57 \pm 1.52$ & $1.57 \pm 4.16$ \\
2 & $0.72 \pm 0.95$ & $0.00 \pm 0.00$ \\
3 & $6.00 \pm 2.91$ & $0.00 \pm 0.00$ \\
4 & $2.57 \pm 4.16$ & $0.14 \pm 0.38$ \\
5 & $1.14 \pm 1.46$ & $4.00 \pm 7.39$ \\
6 & $2.29 \pm 4.49$ & $0.00 \pm 0.00$ \\
7 & - & $1.71 \pm 2.21^{\mathrm{a}}$ \\
a Mean \pm SD total session duration $=21.25 \pm 26.02 \mathrm{~min}$ \\
for this net
\end{tabular}

Only 2 birds interacted with a net underwater, principally by biting or trying to get their head through it. We found no significant differences between nets in the number of total dives per session $\left(\chi^{2}=4.139, \mathrm{df}=\right.$ $5, \mathrm{p}=0.530)$. There were also no significant differences between nets in the number of dives without interactions per session $\left(\chi^{2}=3.904, \mathrm{df}=5, \mathrm{p}=0.563\right)$ and in the number of dives with interactions per session $\left(\chi^{2}=3.158, \mathrm{df}=5, \mathrm{p}=0.676\right)$.

\section{DISCUSSION}

This study, the first to be realized under captive conditions, allowed us to clearly observe bird reactions when facing different types of net, in a controlled and safe environment. We were able to record and quantify their reactions, which would otherwise be very difficult in a natural environment. Birds showed no or little fear of approaching the experimental nets, and all interacted with our set-up. Our study indicates that the best net to use to efficiently and safely exclude common eiders, is a net with a maximum mesh size of 6" with larger twine diameter.

Because no birds went through 6" mesh nets and the majority of them managed to get through 8 " mesh nets, we conclude that the maximum mesh size for a bird of the size of a common eider is 6". One grower in Sweden is using 4 " nets around his farm to a depth of $20 \mathrm{~m}$ to exclude eider ducks (J. Bonardelli pers. obs.). In Scotland, growers used 4" to 6" exclusion nets against eider ducks (Ross \& Furness 2000; J. Bonardelli pers. obs.). However, common eiders are the largest sea ducks. Thus, the mesh size should probably be smaller for smaller species like scoters (900 to $1500 \mathrm{~g}$ ) or long-tailed ducks (500 to $1000 \mathrm{~g}$ ). 
Rueggeberg \& Booth (1989) recommended a maximum mesh size of 4 " for an effective exclusion and prevention of entanglement of scoters. Our recommendation is that further net testing experiments similar to this one should be conducted to determine maximum mesh sizes for effective exclusion of other duck species (e.g. scoters, long-tailed ducks, and goldeneyes Bucephala spp.). Birds interacted with every net, either by passing their head through, or by pushing and biting it. This shows their motivation to interact and find a way to get to the other side. The total number of interactions was not different between mesh sizes, showing that birds interacted with the same intensity with all nets. However, the type of interactions varied with the mesh size. Thus, birds were probably not able to get their head through nets with small mesh sizes (3"), so they principally engaged in other kinds of interactions (pushing or biting). When nets were large enough (5" to $6 ")$, birds tried to get their head through, and often pushed the nets with their whole body. With a larger net $\left(8^{\prime \prime}\right)$, they could probably have passed through completely, but nets less than 6" were effective physical barriers that prevented eiders from passing to the other side. Moreover, our results suggest that birds do not hesitate to interact with exclusion nets, so nets should be strong and safe enough to avoid damage or wear because of birds and bird entanglement. Complementary measures in parallel with exclusion nets may be more effective in preventing birds from entering mussel farms (e.g. frightening methods; Melvin et al. 1999).

Birds did not dive much during this experiment, and only 2 birds interacted with nets underwater. Our captive birds were trained to dive, and did so when mussels were put at the bottom of the holding tank. However, they only dived when they felt safe (e.g. without the experimenter on the platform). Thus our birds preferred to approach and interact with nets from the surface, where they probably felt safer than underwater. However, one of the birds went under the net and showed that birds are able to lift the net and get under it. Even if this was done only once and by only one of our captive birds, this observation shows that birds are able to get under exclusion nets. Moreover, because our experimental birds certainly dived much less than wild birds, which always forage underwater, it seems likely that wild birds would be more disposed to dive in the presence of an exclusion net. Therefore, depth of the net is a factor to consider when installing nets around a farm. This is what Rueggeberg \& Booth (1989) observed in their study, where wild scoters reached the other side principally by diving under exclusion nets, at depths around $10 \mathrm{~m}$. Moreover, Rueggeberg \& Booth (1989) showed that it is also possible for ducks to fly above nets to reach the other side. Indeed, in their study, scoters were able to fly above the $1 \mathrm{~m}$ fence installed at the surface, even if the take-off area was reduced. Therefore, the surface, and at least $1 \mathrm{~m}$ above, should also be protected when considering exclusion nets in a mussel farm. However, observations of the behavior of common eiders around a Norwegian mussel farm showed that the birds would not land within the mussel farm that had over $1 \mathrm{~km}$ of exclusion netting encircling the suspended mussel line system. Instead, the eiders landed safely on the outside of the farm perimeter, and paddled toward the $4 \mathrm{~m}$ deep net. The net was also held $1 \mathrm{~m}$ above the surface and was visible at a distance. None of the birds was seen to dive under the net and pop up within the farm site (J. Bonardelli pers. obs.).

The number of partial entanglements differed between nets, and the 8 " thin-twine net followed by the $6 "$ thin-twine net were the most dangerous nets for our tested birds. This is in agreement with Nemtzov \& Olsvig-Whittaker (2003), who found that net type played an important role in entanglement risk, and that nets with large meshes and small twine were more likely to cause sea bird entanglement. The use of gill nets by growers on a Scandinavian mussel farm was shown to increase underwater entanglement and drowning of birds, a result that made it clear that this material should be avoided ( $\mathrm{J}$. Bonardelli pers. obs.). However, in our study, there were no complete entanglements, either at the surface or underwater, and only few partial entanglements. This is comparable with the study by Rueggeberg \& Booth (1989), in which no underwater entanglement occurred during the experiment and only 3 instances of bird entanglements were observed in the surface fence. Under our experimental conditions, the nets were firmly attached, relatively clean, and of good quality, unlike in open waters where fouling and weather can directly impact net condition and long-term net tension. Indeed, Nemtzov \& Olsvig-Whittaker (2003) concluded that net condition and maintenance also played an important role in the number of entanglements and mortality in exclusion nets. Thus, frequent maintenance, repair, and cleaning procedures of nets should be considered and evaluated prior to installment.

Because our birds showed no apprehension towards approaching the exclusion nets, regardless of the net color, we did not include color as a pertinent parameter in our analyses. Moreover, Rueggeberg \& Booth (1989) did not find evidence of color playing a 
role in bird exclusion and entanglement. Fouling in oceanic water can quickly darken nets and make initial color differences negligible. However, it is possible to make nets more 'visible' for birds by installing a portion above the surface and implementing scaring methods.

Our experiment highlights some elements regarding net choice for bird exclusion in mussel farms. However, other factors need to be considered by growers in their net choice, as follows. (1) Net weight: Mesh size plays an important role in the weight of a net, and nets with smaller mesh are generally heavier. Nevertheless, handling of our nets during the experiment proved that the weight of a net is also strongly determined by the twine diameter and the material of the net (at equal mesh and twine size, polypropylene is lighter than nylon). Thus, 12.5" and 6" thick nylon nets were heavier than the 3 " thin polypropylene net or the $4 "$ thin nylon net. Net weights are given in Table 1. In addition, the material, twine diameter, and mesh size will also impact on the degree of fouling of the net, which will reduce water flow and substantially increase its weight during handling and maintenance. These considerations will vary depending on the site characteristics, and the season and period of time nets remain submerged. (2) Cost: Costs are calculated by weight and type of net (Rueggeberg \& Booth 1989). Prices of new nets (i.e. unused nets) are, in 2013, around US\$ $14.00 \mathrm{~kg}^{-1}$ but can vary with the material used and the manufacturing process. Moreover, it is possible to buy cheaper used nets, but growers should always pay attention to net quality when buying exclusion nets. Indeed, nets of good quality will last longer and be more efficient, and long-term economies will be determined by initially choosing a good net. Rueggeberg \& Booth (1989) estimated that the cost of installing a net represents 16 to $33 \%$ of the yield of the first harvest for a raft, but it represents only 4 to $9 \%$ of the income from $8 \mathrm{yr}$ of harvesting. Mussel rafts can be enclosed more successfully and cost effectively, because the mussels are contained in a small area with the exclusion net wrapped around the existing raft structure. In comparison, separate anchoring and flotation systems must be used to install exclusion nets around longlines, which makes the installation and handling more costly, as well as more challenging to maintain tension, because rough weather and currents have a greater impact on any free-floating structures (J. Bonardelli pers. obs.). (3) Net tangle: Nets with large mesh sizes were more difficult to handle because they were more subject to tangling, especially nets larger than 6". This was also the case for nets with thin twine. Finally, polypropy- lene nets were easier to work with because they were more rigid and less subject to tangling than nylon nets. When installing a net in a mussel farm, all of these factors need to be considered, and the price of acquisition, installation, and maintenance of exclusion nets should be compared to the costs of production losses due to birds.

Although exclusion nets can be an effective solution for important and long-term predation problems, they cannot be used everywhere and should be used cautiously. Indeed, nets in open water can always create problems, especially if they are not correctly attended, and will then require additional time and human intervention. It could be beneficial to use scaring methods in addition to exclusion nets, to discourage birds from approaching exclusion nets (Melvin et al. 1999). Moreover, it is essential to localize bird predation problems at each site, in relation to mussel size and bird numbers, in order to install nets only in high predation risk zones. Understanding the intensity, frequency, and timing of predation at a site (e.g. predator species, periods of high bird abundance, numbers of birds, mussel losses due to birds) can lead to important reductions in cost and labor before installing exclusion nets. This is generally possible as a result of collaboration among growers, bird specialists, and government authorities (Barras \& Godwin 2005, Cox et al. 2007).

Acknowledgements. We thank Morenot and Campbell River Netloft for offering tested nets; Les Moules Cascapédia ltée and Les Moules de Gaspé for supplying mussels and aquaculture material; and C. McKindsey and his team for technical assistance. This study was made possible by a joint initiative of the Norwegian Institute for Nature Research, the Université du Québec à Rimouski, and the Maurice Lamontagne Institute, Fisheries and Oceans Canada. This research was financially supported by the Research Council of Norway. É.V. was also partially supported by a FONCER doctoral fellowship from Réseau Aquaculture Québec. The experimental protocol was approved by the Canadian Council on Animal Care (CPA-38-09-70-R2).

\section{LITERATURE CITED}

Barras SC, Godwin KC (2005) Controlling bird predation at aquaculture facilities: frightening techniques. SRAC Publication 401. Southern Regional Aquaculture Center, Stoneville, MS

Bustnes JO (1998) Selection of blue mussels, Mytilus edulis, by common eiders, Somateria mollissima, by size in relation to shell content. Can J Zool 76:1787-1790

> Cantin M, Bédard J, Milne H (1974) The food and feeding of common eiders in the St. Lawrence Estuary in summer. Can J Zool 52:319-334

Cottam C (1939) Food habits of North American diving ducks. United States Department of Agriculture, Washington, DC 
Cox TM, Lewison RL, Žydelis R, Crowder LB, Safina C, Read AJ (2007) Comparing effectiveness of experimental and implemented bycatch reduction measures: the ideal and the real. Conserv Biol 21:1155-1164

Curtis KS, Pitt WC, Conover MR (1996) Overview of techniques for reducing bird predation at aquaculture facilities. The Jack Berryman Institute, Utah State University, Logan, UT

Dagys M, Žydelis R (2002) Bird bycatch in fishing nets in Lithuanian coastal waters in wintering season 20012002. Acta Zool Litu 12:276-282

Davies RWD, Cripps SJ, Nickson A, Porter G (2009) Defining and estimating global marine fisheries bycatch. Mar Policy 33:661-672

Dionne M (2004) Relationship between diving ducks and mussel aquaculture in Prince Edward Island, Canada. MSc thesis, University of New Brunswick, Fredericton

$>$ Draulans D (1987) The effectiveness of attempts to reduce predation by fish-eating birds: a review. Biol Conserv 41:219-232

Dunthorn AA (1971) The predation of cultivated mussels by eiders. Bird Study 18:107-112

Falker TS, Brittingham MC (1998) Controlling birds at aquaculture facilities. The Pennsylvania State University, State College, PA

FAO (Food and Agriculture Organization of the United Nations) (2003) État de l'aquaculture dans le monde. Organisation des Nations Unies pour l'alimentation et l'agriculture, Département des pêches et de l'aquaculture de la FAO. FAO, Rome

FAO (2010) World aquaculture. Organisation des Nations Unies pour l'alimentation et l'agriculture, Département des pêches et de l'aquaculture de la FAO. FAO, Rome

FAO (2012) La situation mondiale des pêches et de l'aquaculture. Organisation des Nations Unies pour l'alimentation et l'agriculture, Département des pêches et de l'aquaculture de la FAO. FAO, Rome

Galbraith C (1992) Mussel farms: their management alongside eider ducks. Scottish Natural Heritage, Edinburgh

Gorenzel WP, Conte FS, Salmon TP (1994) Bird damage at aquaculture facilities. University of Nebraska, Lincoln, NE

Guillemette M (1994) Digestive-rate constraint in wintering common eider (Somateria mollissima): implications for flying capabilities. Auk 111:900-909

Guillemette M (2001) Foraging before spring migration and before breeding in common eiders: Does hyperphagia occur? Condor 103:633-638

Guillemette M, Ouellet JF (2005) Temporary flightlessness as a potential cost of reproduction in pre-laying common eiders Somateria mollissima. Ibis 147:301-306

Guillemette M, Himmelman JH, Barette C, Reed A (1993) Habitat selection by common eiders in winter and its interaction with flock size. Can J Zool 71:1259-1266

Guillemette M, Reed A, Himmelman JH (1996) Availability and consumption of food by common eiders wintering in the Gulf of St Lawrence: evidence of prey depletion. Can J Zool 74:32-38

> Hall MA (1996) On bycatches. Rev Fish Biol Fish 6:319-352

- Hamilton DJ, Nudds TD, Neate J (1999) Size-selective predation of blue mussels (Mytilus edulis) by common eiders (Somateria mollissima) under controlled field conditions. Auk 116:403-416

Jamieson SE, Gilchrist HG, Merkel FR, Diamond AW, Falk

Editorial responsibility: Pablo Sánchez Jerez,

Alicante, Spain
K (2006) Endogenous reserve dynamics of northern common eiders wintering in Greenland. Polar Biol 29: 585-594

> Kirk M, Esler D, Boyd WS (2007) Morphology and density of mussels on natural and aquaculture structure habitats: implications for sea duck predators. Mar Ecol Prog Ser 346:179-187

Larsen JK, Guillemette M (2000) Influence of annual variation in food supply on abundance of wintering common eiders Somateria mollissima. Mar Ecol Prog Ser 201: 301-309

Leopold MF, Kats RKH, Ens BJ (2001) Diet (preferences) of common eiders Somateria mollissima. Wadden Sea Newslett 1:25-31

Littauer GA, Glahn JF, Reinhold DS, Brunson MW (1997) Control of bird predation at aquaculture facilities: strategies and cost estimates. Southern Regional Aquaculture Center, Stoneville, MS

Lutz RA (ed) (1980) Mussel culture and harvest: a North American perspective. Developments in aquaculture and fisheries science, Vol 7. Elsevier Scientific Publishing, Amsterdam

Mallet A, Myrand B (1995) The culture of the blue mussel in Atlantic Canada. In: Boghen AD (ed) Cold-water aquaculture in Atlantic Canada. The Canadian Institute for Research on Regional Development, Moncton, p 256-295

Melvin EF, Parrish JK, Conquest LL (1999) Novel tools to reduce seabird bycatch in coastal gillnet fisheries. Conserv Biol 13:1386-1397

Merkel FR (2004) Impact of hunting and gillnet fishery on wintering eiders in Nuuk, Southwest Greenland. Waterbirds 27:469-479

> Nemtzov SC, Olsvig-Whittaker L (2003) The use of netting over fishponds as a hazard to waterbirds. Waterbirds 26:416-423

> Nilsson L (1972) Habitat selection, food choice, and feeding habits of diving ducks in coastal waters of South Sweden during the non-breeding season. Ornis Scand 3:55-78

Price IM, Nickum JG (1995) Aquaculture and birds: the context for controversy. Colon Waterbirds 18:33-45

R Development Core Team (2009) R: a language and environment for statistical computing. R Foundation for Statistical Computing, Vienna

Ross BP, Furness RW (2000) Minimising the impact of eider ducks on mussel farming. University of Glasgow

Rueggeberg H, Booth J (1989) Marine birds and aquaculture in British Columbia: preventing predation by scoters on a west coast mussel farm. Canadian Wildlife Service, Pacific and Yukon Region, Delta

Spencer BE (2002) Molluscan shellfish farming. Blackwell Publishing, Oxford

Vermeer K, Bourne N (1984) The white-winged scoter diet in British Columbia waters: resource partitioning with other scoters. In: Nettleship DN, Sanger GA, Springer PF (eds) Marine birds: their feeding ecology and commercial fisheries relationships. Proceedings of The Pacific Seabird Group Symposium, Seattle, WA, 6-8 January 1982. Canadian Wildlife Service Special Publication, Ottawa, p 30-38

Žydelis R, Bellebaum J, Österblom H, Vetemaa $M$ and others (2009) Bycatch in gillnet fisheries - an overlooked threat to waterbird populations. Biol Conserv 142: 1269-1281

Submitted: December 7, 2012; Accepted: May 6, 2013

Proofs received from author(s): June 3, 2013 